Document downloaded from:

http://hdl.handle.net/10251/89672

This paper must be cited as:

Yepes Piqueras, V.; Martí Albiñana, JV.; García Segura, T.; González Vidosa, F. (2017). Heuristics in optimal detailed design of precast road bridges. Archives of Civil and Mechanical Engineering. 17:738-749. doi:10.1016/j.acme.2017.02.006

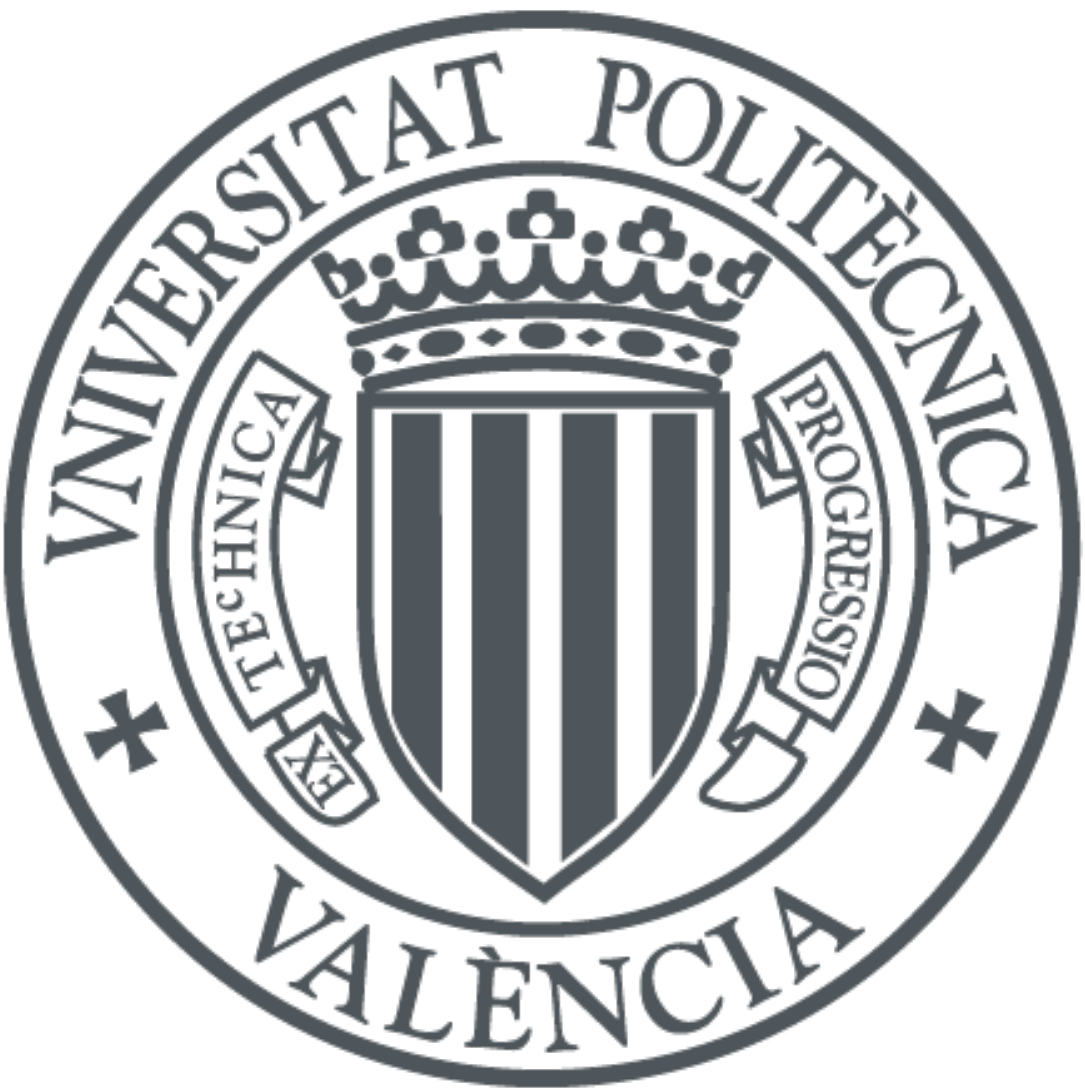

The final publication is available at

https://doi.org/10.1016/j.acme.2017.02.006

Copyright

Additional Information 


\title{
HEURISTICS IN OPTIMAL DETAILED DESIGN OF PRECAST ROAD BRIDGES
}

\author{
V. Yepes ${ }^{1}$ \\ J.V. Martî \\ T. García-Segura ${ }^{3}$ \\ F. González-Vidosa ${ }^{4}$
}

\begin{abstract}
This paper deals with the cost optimization of road bridges consisting of concrete slabs prepared in situ and two precast-prestressed U-shaped beams of self-compacting concrete. It shows the efficiency of four heuristic algorithms applied to a problem of 59 discrete variables. The four algorithms are the Descent Local Search (DLS), a threshold accepting algorithm with mutation operation (TAMO), the Genetic Algorithm (GA), and the Memetic Algorithm (MA). The heuristic optimization algorithms are applied to a bridge with a span length of $35 \mathrm{~m}$ and a width of $12 \mathrm{~m}$. A performance analysis is run for the different heuristics, based on a study of Pareto optimal solutions between execution time and efficiency. The best results were obtained with TAMO for a minimum cost of $104184 €$. Among the key findings of the study, the practical use of these heuristics in real cases stands out. Furthermore, the knowledge gained from the investigation of the algorithms allows a range of values for the design optimization of such structures and pre-dimensioning of the variables to be recommended.
\end{abstract}

\section{Keywords}

Optimization; metaheuristics; bridges; overpasses; structural design.

\section{Introduction}

Precast-prestressed concrete (PPC), that is, pretensioned concrete beams with cast-in-situ slabs, has been commonly used by designers when building road bridges [1]. In this context, structural engineers have taken advantage of precast technology by specifying designs that utilize standard beams of comparatively short spans, typically ranging from 10 to over $40 \mathrm{~m}$. Moreover, reducing the material weight through

\footnotetext{
${ }^{1}$ Associate Professor, Institute of Concrete Science and Technology (ICITECH), Universitat Politècnica de València, 46022 Valencia, Spain. Corresponding author. Phone +34963879563; Fax: +34963877569; E-mail: vyepesp@cst.upv.es

${ }^{2}$ Associate Professor, Institute of Concrete Science and Technology (ICITECH), Universitat Politècnica de València, 46022 Valencia, Spain. E-mail: jvmartia@cst.upv.es

${ }^{3}$ Graduate Research Assistant, Institute of Concrete Science and Technology (ICITECH), Universitat Politècnica de València, 46022 Valencia, Spain. E-mail: tagarse@cam.upv.es

${ }^{4}$ Professor, Institute of Concrete Science and Technology (ICITECH), Universitat Politècnica de València, 46022 Valencia, Spain. E-mail:E-mail: fgonzale@cst.upv.es
} 
prestressing is decisive due to transportation and elevation costs. This is where structural optimization of this type of large and repetitive structure becomes especially relevant.

The basic goal of structural optimization is to find a design having lowest cost, and ensuring predicted constraints. Additionally, in most structural optimization problems, the main drawback appears to be related to the constructability of the proposed design such as reinforcement placement, rules of good design practice, construction management plan, and so on [2]. The decisions taken in such a complex environment require the development of new decisional tools and methods that provide more effective and realistic solutions $[3,4]$. Among the available computational methods that can be used to solve optimization problems, heuristics and metaheuristics are approximate methods that are considered as particularly useful algorithms in structural engineering [5].

The earliest studies into structural reinforced concrete (RC) optimization date back to the late 1990s [6,7]. However, Cohn and Dinovitzer [8] identified a great gap between theoretical work and the practical application of structural optimization. Recent research has been conducted with regard to heuristics and metaheuristics [9], such as Descent Local Search (DLS) [10], Genetic Algorithms (GAs) [11,12], evolutionary algorithms [13,14], Simulated Annealing (SA) [15,16], Variable Neighborhood Search (VNS) [17], Harmony Search (HS) [18, 19], Ant Colony Optimization (ACO) [20], Glowworm Swarm Algorithm (GSA) [21], Eagle Strategy (ES) [22], and the Big Bang-Big Crunch algorithm (BB-BC) [23], among others.

Despite the aforementioned research works, there is still limited knowledge on the optimization of prestressed concrete (PC) bridge structures. Hassanain and Loov [24] reviewed research on cost optimization of concrete bridge structures; nevertheless, as Hernandez et al. [25] have noted, most approaches for PC bridges found in the literature are not suitable for application in real-life engineering. Ohkubo et al. [26] studied PC box girder bridges and proposed a multi-criteria fuzzy optimization of the total construction cost and aesthetic feeling. Sirca and Adeli [27] and Ahsan et al. [28] focused on the optimal-cost design of concrete I-girder bridges. Both used PPC for the beams; the latter also used posttensioned tendons. García-Segura et al. [29] proposed a hybrid HS for the design of post-tensioned concrete box-girder pedestrian bridges. Martí et al. [30] used a hybrid SA to minimize the cost of PC precast Ubeam road bridges. 
In this line of work, this paper focuses on the cost optimization of PPC road bridges. The PPC bridge system studied consists of two PC U-beams with a span length of $35 \mathrm{~m}$ and a top slab formed by a $0.06 \mathrm{~m}$ precast $\mathrm{RC}$ slab used as formwork for the cast-in-place RC slab (Figure 1). Beams are made of self-compacting concrete. The top slab allows vehicle traffic and has a width of $12 \mathrm{~m}$ (Figure 2). The optimization searches for the geometric variables, concrete, and steel that minimize the cost. A module evaluating all relevant limit states has been implemented, and subsequently metaheuristics that are capable of finding costoptimized solutions have been developed specifically for this work.

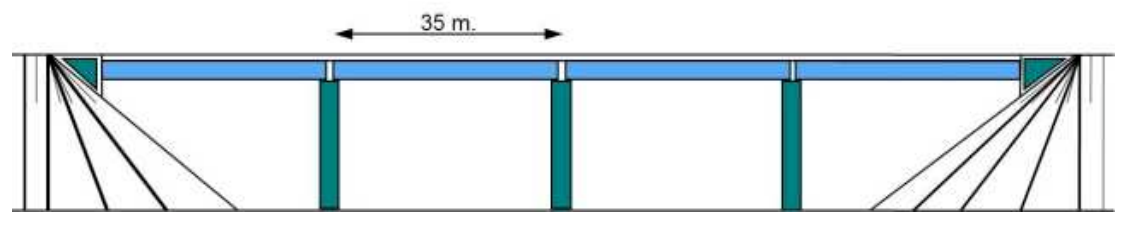

Figure 1. Longitudinal profile of the bridge

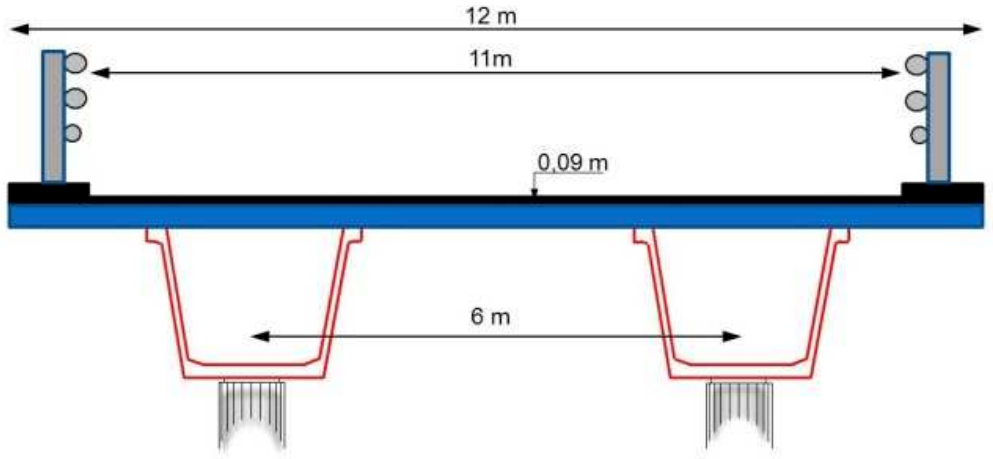

Figure 2. Cross section of the beam-slab deck

\section{Definition of the problem}

The mathematical problem is comprised of economical optimization of the structure, represented by the objective function $f$ in Eq. (1) while satisfying the constraints in Eq. (2).

$$
\begin{aligned}
& C=f\left(x_{1}, x_{2}, \ldots, x_{n}\right) \\
& g_{j}\left(x_{1}, x_{2}, \ldots . x_{n}\right) \leq 0 \\
& x_{i} \in\left(d_{i 1}, d_{i 2}, \ldots, d_{i q_{i}}\right)
\end{aligned}
$$

Note that $x_{1}, x_{2}, \ldots, x_{\mathrm{n}}$ are the design variables whose combination is to be optimized. Each variable can take on the discrete values listed in Eq. (3). 
The objective function considered is the cost function defined in Eq. (4), where $p_{i}$ are the unit prices; $m_{i}$ are the measurements of the units in which the construction of the PCC bridge is split, and $r$ is the total number of construction units.

$$
C=\sum_{i=1, r} p_{i} \times m_{i}
$$

The cost of the bridge depends on the material volumes used as well as the labour, machinery, and resources necessary for the construction. The cost function is obtained by adding the price of each unit multiplied by the respective measurements (Table 1). As discrete values are used to guarantee the constructability, this is a combinatorial optimization problem.

The analysis includes 59 design variables. Figure 3 shows the main geometric variables considered in this analysis. The seven geometric variables comprise the depth of the beam $\left(h_{1}\right)$, the thickness of the slab $\left(e_{4}\right)$, the width of the soffit of the beam $\left(b_{1}\right)$ and its thickness $\left(e_{1}\right)$, the width and thickness of the flanges $\left(b_{3}\right.$ and $e_{3}$ ), and the thickness of the webs $\left(e_{2}\right)$. Regarding the material strength, there are two variables that define the concrete grades used for the slab and the girder. There are 46 variables that define the standard reinforcement setup in the beams and slab. Figure 3 shows the top $\left(A s_{6}\right)$ and bottom $\left(A s_{7}\right)$ longitudinal passive reinforcement of slab, the top $\left(t_{4}\right)$ and bottom $\left(t_{5}\right)$ transverse reinforcement of slab, and the transverse reinforcement of the bottom flange $\left(t_{1}\right)$, web $\left(t_{2}\right)$ and the top flange $\left(t_{3}\right)$ of beam. The prestressing steel, which is formed by 0.6-inch strands, is defined by four variables representing: (1) the number of strands in the top flanges (level 4), (2) the number of strands in the bottom flange (levels 1-3), (3) the number of sections with strand sheaths (non-bonded steel) in the second, and (4) third layers of the bottom flange. Each strand is prestressed to $189.40 \mathrm{kN}$. All of the variables of this analysis are discrete and can adopt a range of values, giving rise to $1.6 * 10^{65}$ possible solutions. This large number of solutions justifies the application of a heuristic algorithm to find cost-effective results within a reasonable computation time. 


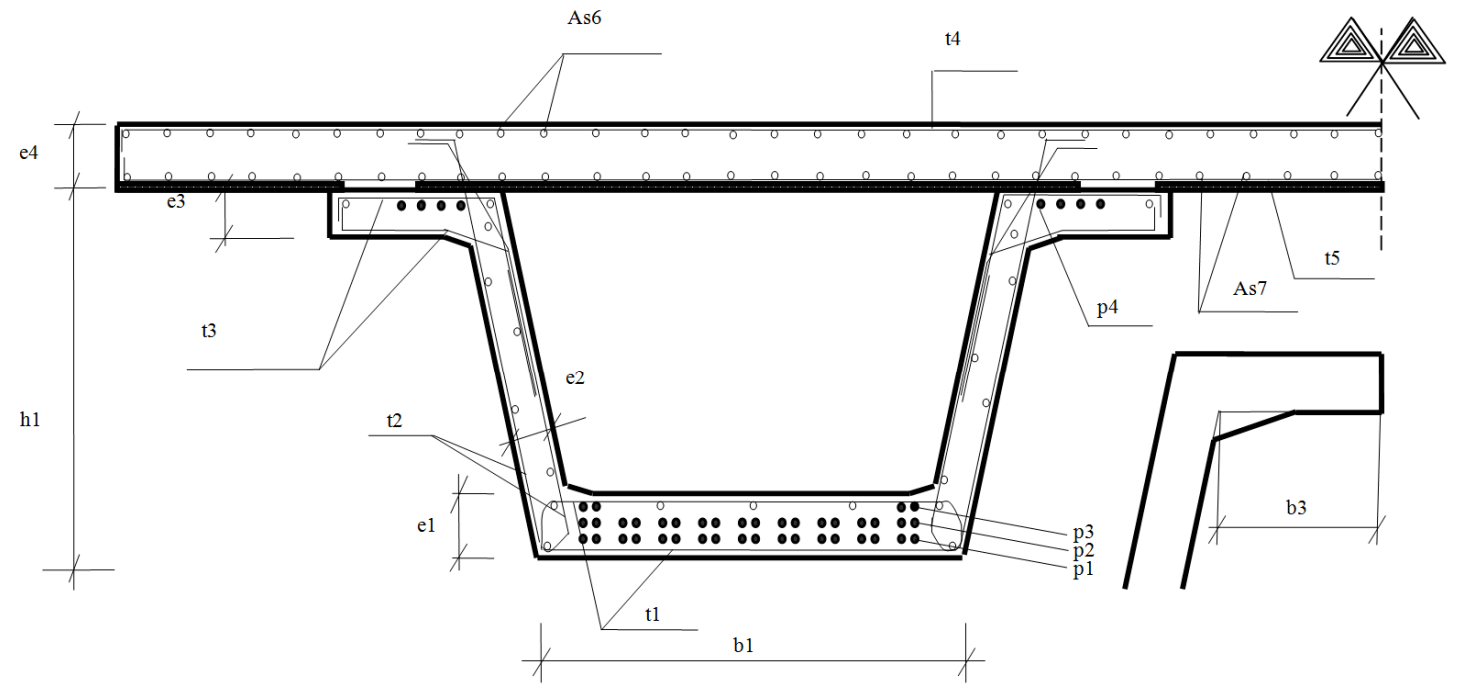

Figure 3: Geometric variables of the beam structure

The main parameters are divided into geometry, loading, cost, reinforcement, and exposure parameters. These include the width of the deck, inclination of the webs, span length, slenderness of the beam, dead loads, transport distance, and steel types. The beam parameters are chosen to facilitate the adjustment of their design to the existing precast molds. The durability requirements are those demanded by the concrete code EHE-08 [31]. The slenderness of the beam is limited to a minimum of $L / 18$ due to aesthetic ground and specific road transportation considerations, where $L$ is the span length. Otherwise, the optimization algorithm tends to increase continuously the depth of the beam, particularly for short span bridges. The details of the parameters can be found in Martí et al. [30] (Table 2).

The structural constraints of IAP-98 [32] include the verifications of the ultimate and serviceability limit states for bending, shear, and torsion as well as fatigue, cracking, and deflection resulting from the dead and traffic loads. It is also tested both flexural and shear minimum amounts of reinforcement, as well as the minimum geometric requirement. The design live load consists of three axis of $200 \mathrm{kN}$ each $(1.5 \mathrm{~m}$ distance between axes), superimposed with a uniform load of $4.0 \mathrm{kN} / \mathrm{m}^{2}$. The dead load is a wearing surface of 0.09 $\mathrm{m}$ as well as a uniformly distributed load of $2 \times 0.5 \mathrm{kN} / \mathrm{m}$ for concrete bridge barrier rails installed along the edge of the deck. Precast RC slabs of $0.06 \mathrm{~m}$ width were considered for the formwork of the top concrete slab. The general exposure class was IIb, according to the Spanish code on structural concrete [31]. The stresses and reactions are obtained from a self-developed program that considers different stress states that occur during the manufacture and placement of the beams. The calculations for the decompression limit state comprise verifying that under the combination of actions corresponding to the phase being studied, 
decompression does not occur in the concrete in any fiber in the section. Temporary deflections were limited to $1 / 250$ of the free span length for the frequent combination. Further, time-dependent deflections were limited to $1 / 1000$ of the free span length for the quasi-permanent combination. The durability limit state was checked according to the working life design, which was checked at each iteration.

The construction sequences and the long-term interaction between the precast beam and the cast-in-place concrete were considered to design the elements and analyze the structural response of the bridge in each phase. The program uses two models for the analysis according to the work by Martí et al. [30]. Figure 4 shows the first model used for a linear elastic analysis of the beam before being connected to the slab. This model is composed of 20 beam elements and 21 nodes. In this phase, the elastic shortening of concrete was considered when calculating the short-term prestress loss. The second model calculated stress resultants and reactions taking into account long-term prestress loss due to creeping and shrinkage of concrete and prestressing steel relaxation by a stiffness matrix program using a 2-D mesh with 20 bar elements and 21 sections for each beam, which are connected with three bar elements for each of the 21 sections. Figure 5 shows a detail of the entire bar model with 103 bar elements and 84 nodes, for which a linear elastic analysis including gross section properties was used. This grillage model was used to represent the mechanical characteristics of the bars in which the longitudinal stresses due to the distortion of the cross-section were considered. The program has been programmed with Fortran 95 and Compaq Visual Fortran Professional 6.6.0 on a personal computer that contains an Intel Core TM2 Quad CPU Q6600 2.40 GHz processor.
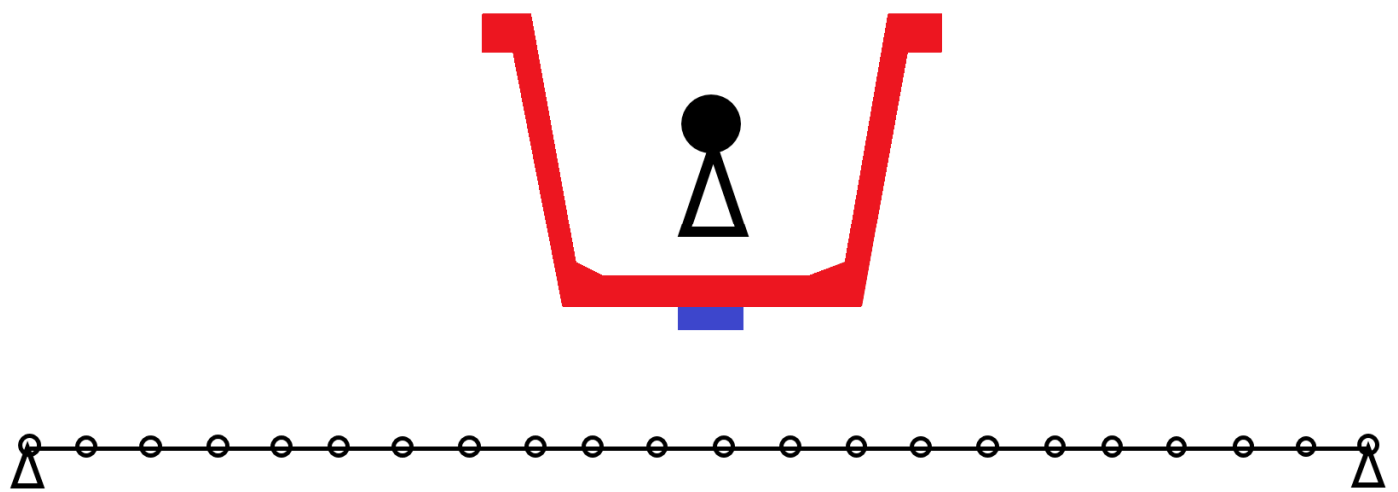

Figure 4: First model used for the analysis of the beam before being connected to the slab 


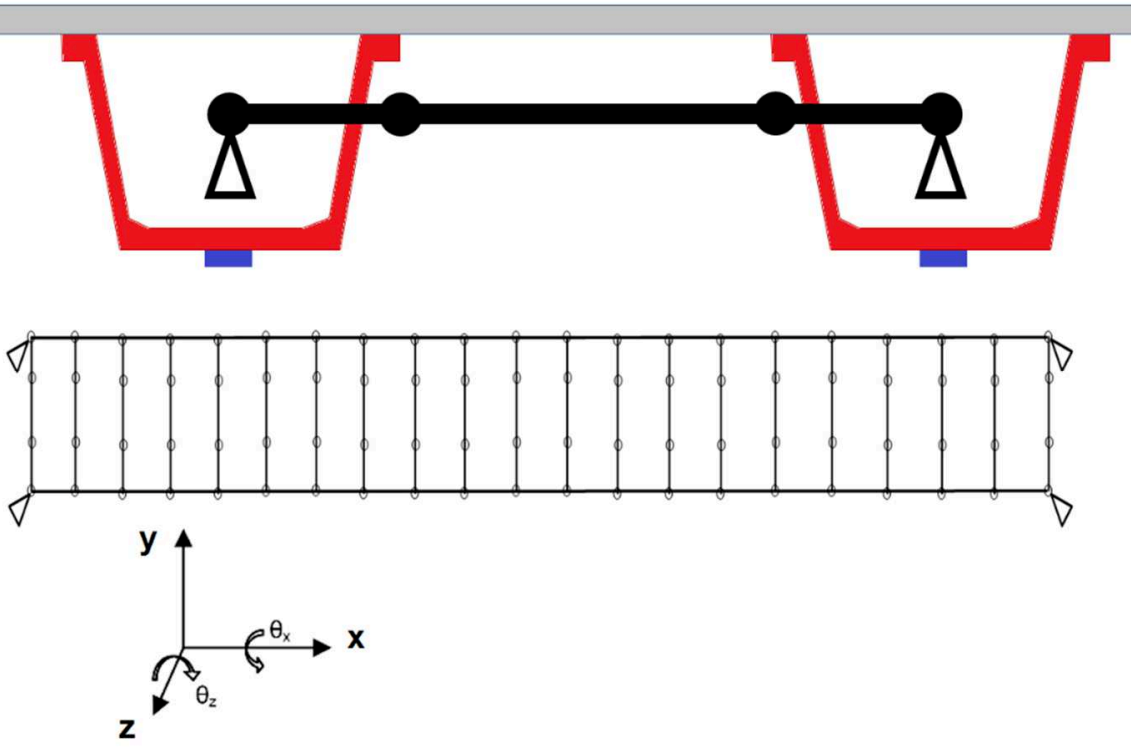

Figure 5: Second model detail for deck long-term analysis

\section{Applied heuristic search methods}

\subsection{Descent Local Search (DLS)}

This algorithm (Figure 6) begins with obtaining a random solution. A small movement, which modifies a fixed number of randomly chosen variables, changes each variable by either increasing or decreasing it by a step or unit. If the new solution has lower cost and is feasible after checking the restrictions, the working solution replaces the previous one. This process is repeated until no further improved solution can be found for a given number of iterations. To account for the random component of the method, the process is repeated nine times according to the methodology proposed by Payá-Zarforteza et al. [33]. It is known that this heuristic becomes trapped in a local optimum, but the main aim of this method is to choose the most efficient moves for incorporation into the threshold acceptance algorithm. 


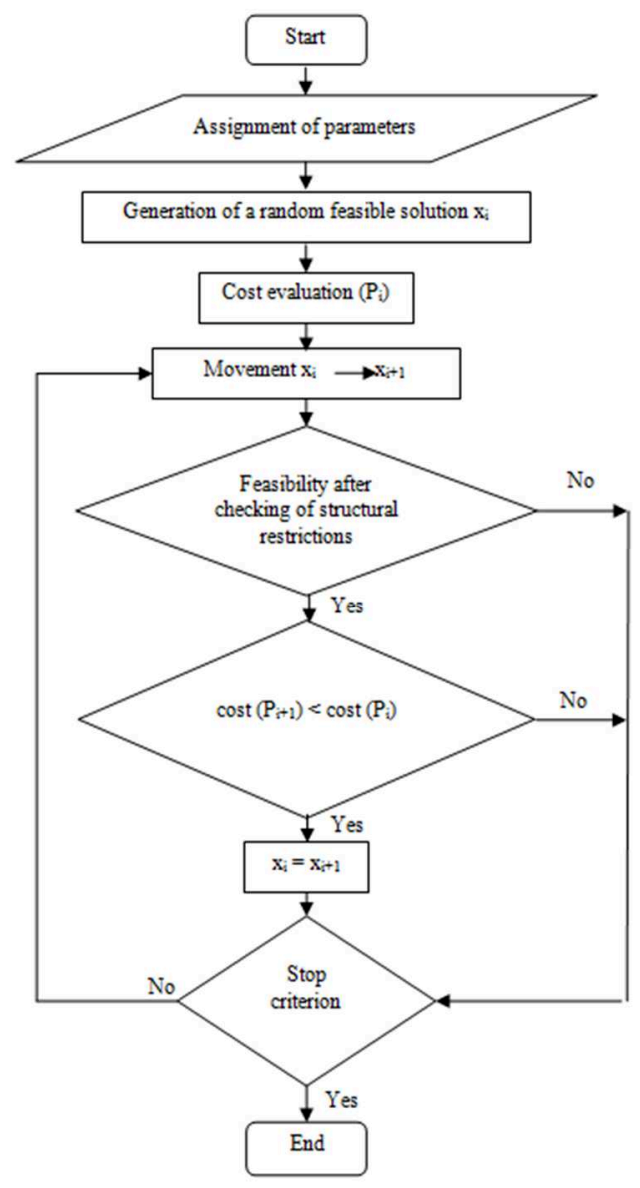

Figure 6: Flowchart of the DLS process

The movements set out in this study modify $5,10,15,20,25$, or $30 \%$ of the variables. The termination criterion is defined as the number of consecutive iterations without cost improvement. Figure 7 shows the average cost values according to the movement and termination criteria. The Pareto optimal solutions with the best trade-off between cost and time correspond to V9-5000 iterations, V12-10000 iterations, and V1215000 iterations. Note that the nomenclature $V n-i$ corresponds to the number of variables $(n)$ and the number of consecutive iterations without cost improvement (i). V9-5000 iterations exhibit a resulting cost of $134529 €$ and need 790 seconds of computation time. Although further cost reductions of 1.6 and $2.8 \%$ are achieved by the next Pareto solutions (V12-10000 iterations and V12-15000 iterations), the computing time increases significantly by $72.2 \%$ and more than $200 \%$, respectively. The best solution (115459€) was obtained by varying $15 \%$ of the variables (V9). V9 is chosen as the best movement. 


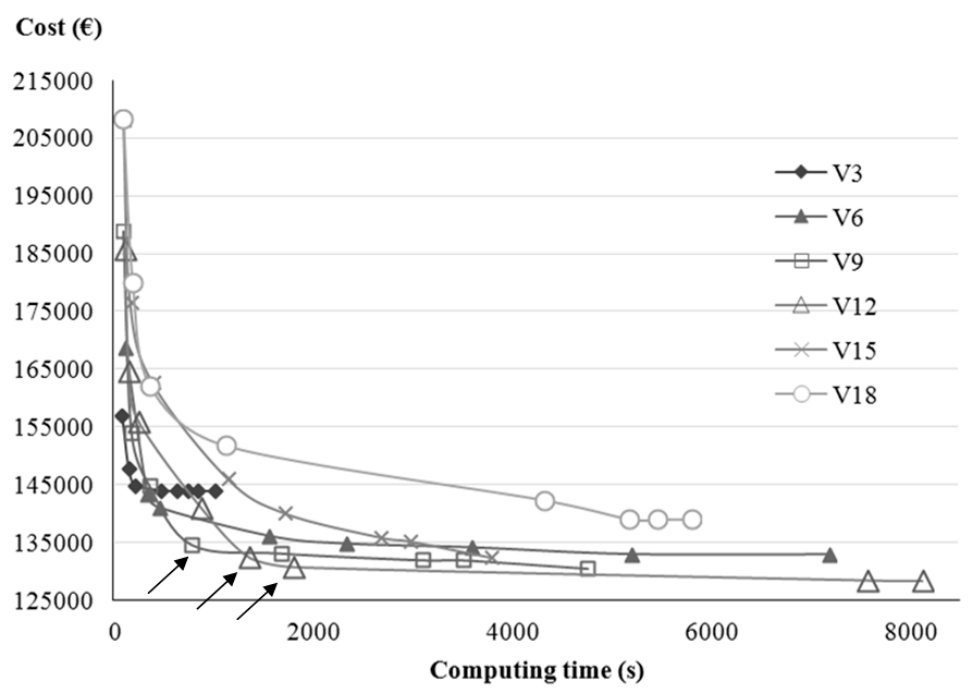

Figure 7: Cost evolution of the DLS algorithm for different movements and termination criteria

\subsection{Threshold Accepting algorithm with Mutation Operation (TAMO)}

The Threshold Accepting (TA) algorithm was originally described by Dueck and Scheuer [34]. The initial threshold $\left(\mathrm{U}_{0}\right)$ is adjusted by Medina's criterion [35], which consists in halving or doubling the initial temperature until the acceptance range is between 20 and 40\%. After applying a movement, the current solution is then checked against structural restrictions. The new solution is accepted if the conditions of feasibility and threshold are satisfied. The threshold decreases gradually during the optimization process according to a reduction coefficient $\left(\alpha_{\mathrm{TA}}\right)$. The TA method is also capable of surpassing local optima and gradually converges as the threshold value decrease to zero.

TAMO combines the TA algorithm with a local search strategy based on the mutation operator that is used in the GA. Figure 8 shows a flowchart of this algorithm. The GA explores the solution space using a population of solutions and operators such as selection, crossover, and mutation. TA hybridization was previously applied by Luz et al. [36] to optimize bridge abutments. The procedure followed for the calibration was the same as that applied in DLS. The best movement was V9. 


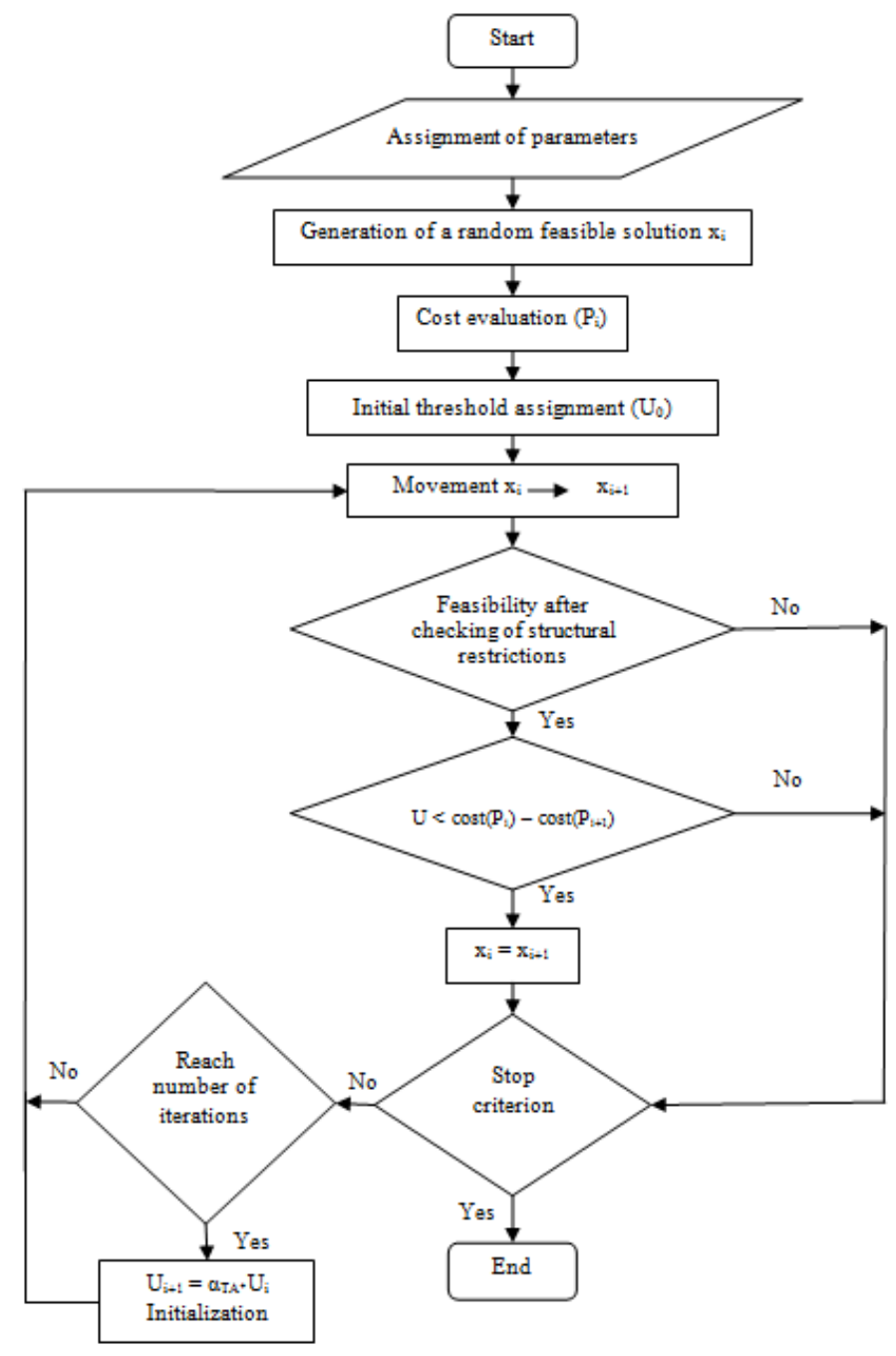

Figure 8: Flowchart of the TAMO process

The application of the TAMO algorithm requires the definition of the threshold coefficient value $\left(\alpha_{\mathrm{TA}}\right)$ as well as the iteration chain $\left(\mathrm{L}_{\mathrm{I}}\right)$. For the first random solution, a temperature equal to $0.5 \%$ of the cost is taken. This criterion allows $\mathrm{U}_{0}$ to be fixed in two chains. Figure 9 shows a typical curve of cost reduction and threshold decrease following TAMO. As the stop criterion, simultaneous compliance with two requirements is implemented: first, a threshold lower than $2 \%$ of the initial threshold $\mathrm{U}_{0}$, and second, two chains without improving the best solution. Table 3 shows the results of a 16 case-study series as well as the minimum, mean, and deviation (MD) of the mean with respect to the minimum for the costs. 


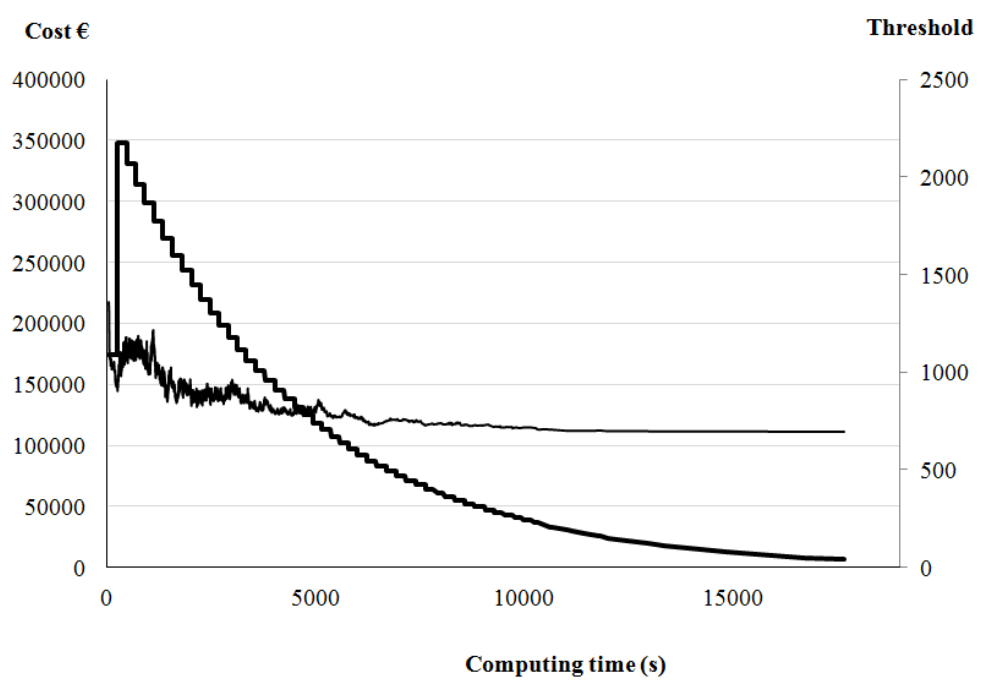

Figure 9: Typical cost variation and threshold reduction for TAMO

The lowest cost, which is $104,184 €$, was obtained using $\mathrm{L}_{\mathrm{I}}=5,000$ and $\alpha_{\mathrm{TA}}=0.95$ (T4). This value was obtained after running TAMO algorithm 400 times. However, it is possible to run the algorithm nine times for each span length instead of 400 times in order to achieve a balance between the quality of the results and the amount of computing time required to obtain them, according to the methodology proposed by Payá-Zarforteza et al. [33]. The difference checked between the minimum cost obtained with the nine TAMO runs of the heuristic number T4 (Table 3), and the extreme value estimated using the threeparameter Weibull distribution that fits 400 TAMO results is less than $1.83 \%$. For these parameters, the average cost is also the minimum, 107,856€. For the same problem [30], the hybrid Simulated Annealing with Mutation Operation (SAMO) achieved the lowest cost of 108,008€ (S12) with a Markov Chain (MC) $=5,000$ and coefficient reduction $\left(\alpha_{\mathrm{SA}}\right)=0.85$, while the best average cost was $110,477 €(\mathrm{~S} 3)$ with $\mathrm{MC}=$ 2,500 and $\alpha_{\mathrm{SA}}=0.95$. Figure 10 shows the average cost values versus time of the results obtained by applying different parameter combinations for SAMO and TAMO strategies. Five Pareto solutions are highlighted. All of them belong to TAMO. The average costs of the 16 combinations of SAMO and TAMO are $115709 €$ and $112021 €$ respectively. This means that the average cost is $3.2 \%$ lower when applying TAMO. In addition, TAMO obtained similar computing times to the SAMO algorithm. 


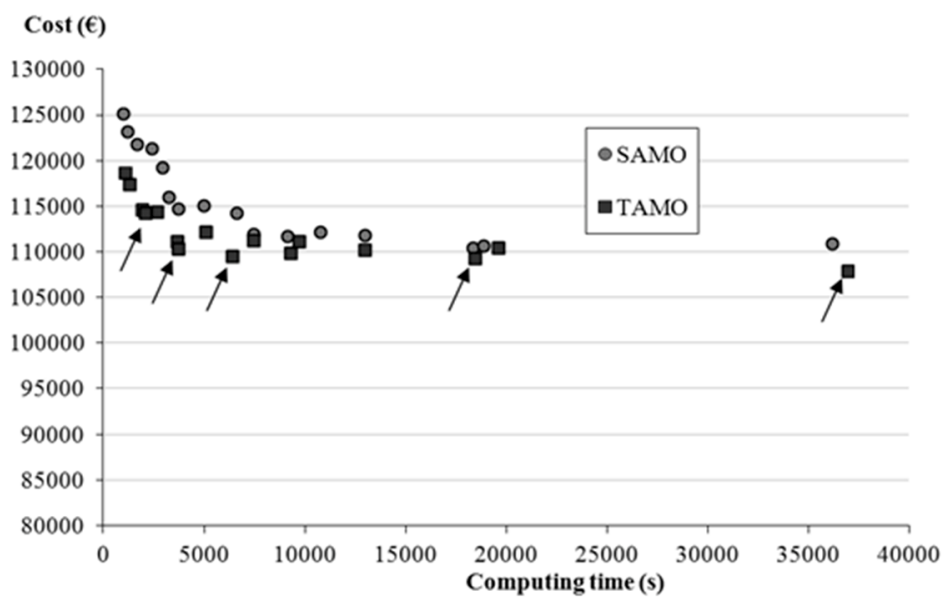

Figure 10: Average costs of SAMO and TAMO for the 16 different combinations

\subsection{Genetic Algorithm (GA)}

This metaheuristic technique was proposed by Holland [37], inspired by the process of natural evolution. Individuals of a population evolve through genetic crossover and mutation, creating better-adapted individuals. The new population is selected in an elitist way. The probability of selecting each individual is proportional to its aptitude. The method, therefore, gives higher probability to the selection of the best solutions of the current population. The crossover operation decides which information is transferred from these two individuals to the new solution. The mutation operator randomly changes some characteristics of the new solution. Penalties are implemented for the infeasible solutions, worsening their aptitude according to a penalty function (Eq. (5)).

$$
C p(k)=C(k)\left(1.1+\frac{1}{f}\right)
$$

$C_{p}(k)$ is the penalized cost of the unfeasible " $k$ " solution, $C(k)$ is the unpenalized cost, and " $f$ ' is a penalty factor that depends on the feasibility of the solution. The penalty factor is equal to the minimum limit state factor, which is obtained as the ratio between the resistance of the structural response and the load effect of actions. The penalty factor is smaller than one for an unfeasible solution. This coefficient reduces the divergence caused by the high sensitivity of the unfeasible PC structures. Other penalty functions were tried without improving the convergence to the minimum. Figure 11 shows a flowchart of this algorithm. 


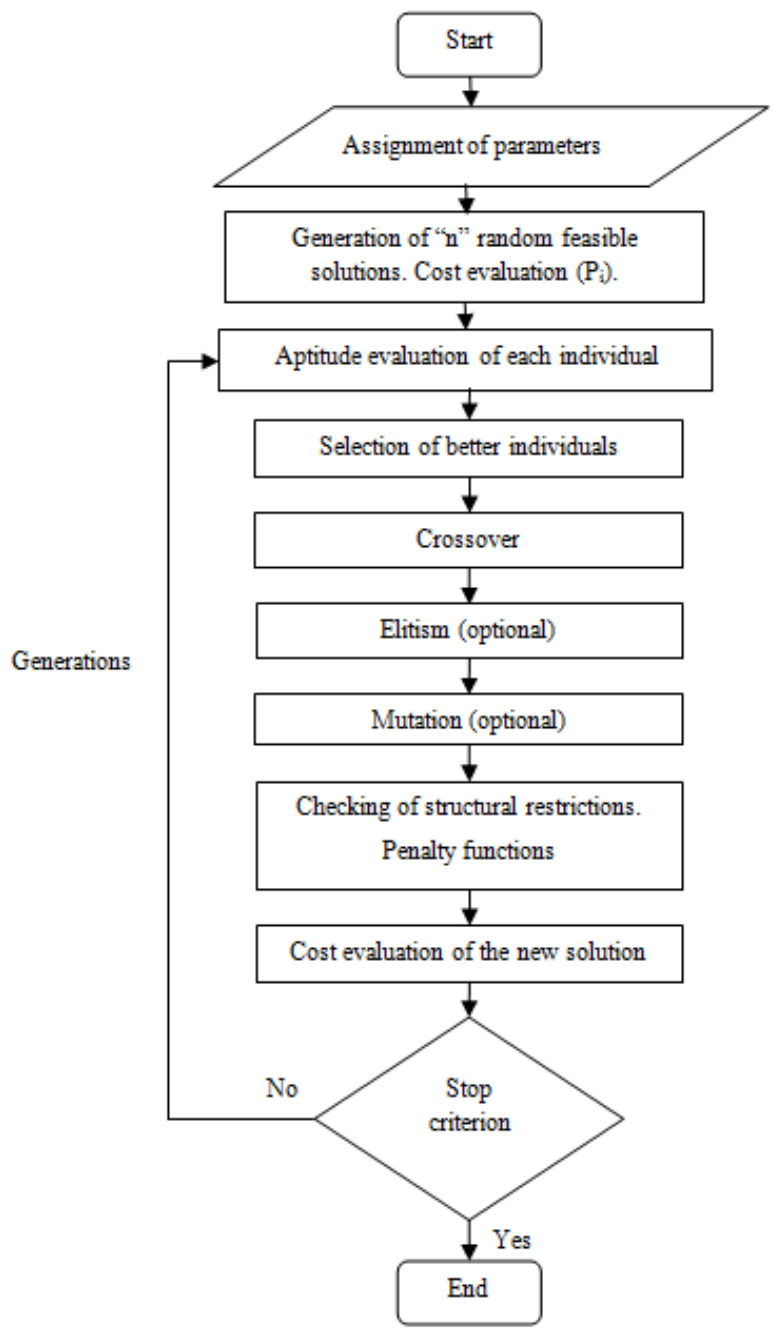

Figure 11: Flowchart of the GA process

First, nine executions with crossover values of $0.25,0.50$, and 0.75 and population sizes of 100,250 , and 500 individuals have been performed. Results are taken for 25, 50, 75, 100, 125, 150, 175, and 200 generations. For this first analysis, mutation has not been considered. Elitism and mutation have been selected as optional. Regarding the population size, the average cost improves and the computing time increases as the number of individuals increases. Table 4 summarizes the results for a population size of 500 individuals. On some occasions, elitism reduces the minimum value. Compared to non-elitism, solutions are $3.1 \%$ cheaper.The best average cost $(138743 €)$ is obtained for 200 generations, a crossover value of 0.5 , and elitism.

A second analysis is carried out to examine the benefits of mutation. The best parameters obtained in the first analysis are selected. These are 500 individuals, a crossover value of 0.5 , and 200 generations. The number of variables subjected to mutation is tracked sequentially. Table 5 shows the results for each 
mutation step. The best improvement with regard to the cost value without mutation is mutation $=4$. Figure 12 represents the evolution of the best GA heuristic (mutation $=4$ ) for both average and minimum costs.

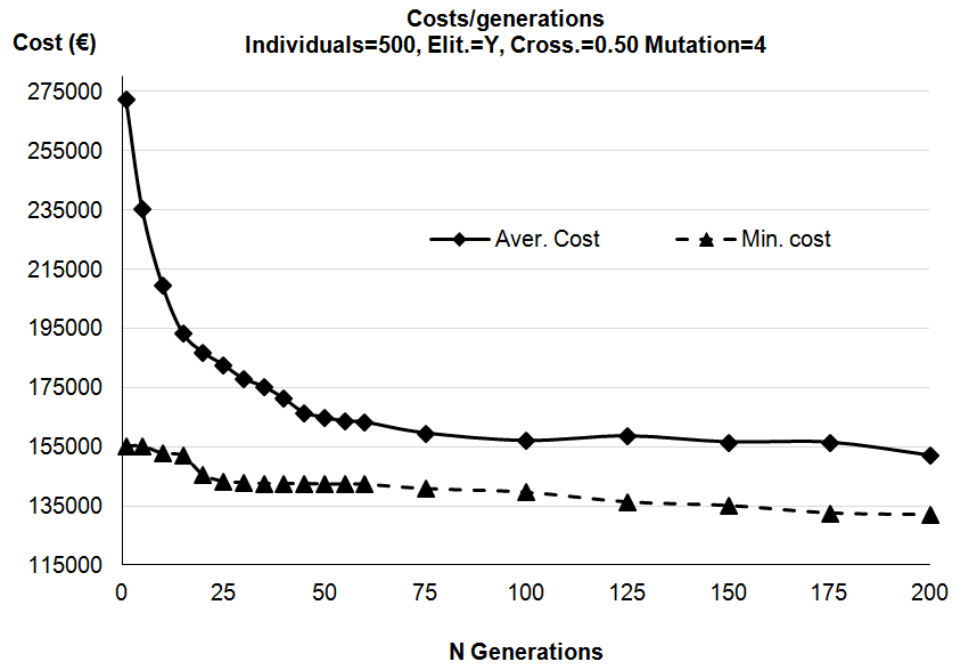

Figure 12: The evolution of average and minimum costs of a GA

\subsection{Memetic Algorithm (MA)}

MA [38] combine population-based global search and local search metaheuristics. Figure 13 shows a flowchart of this algorithm. The process starts with population generation. Each individual is improved through a local search with the purpose of getting closer to a local optimum. The new better-quality population initiates the GA procedure. The goal of combining both strategies is to acquire good genes for the parents (local search), which are then combined to improve the quality of the following generations (population-based global search). This algorithm use the same operators as GA, which are crossover and mutation. The TAMO technique has been used in this algorithm for the local search strategy. 


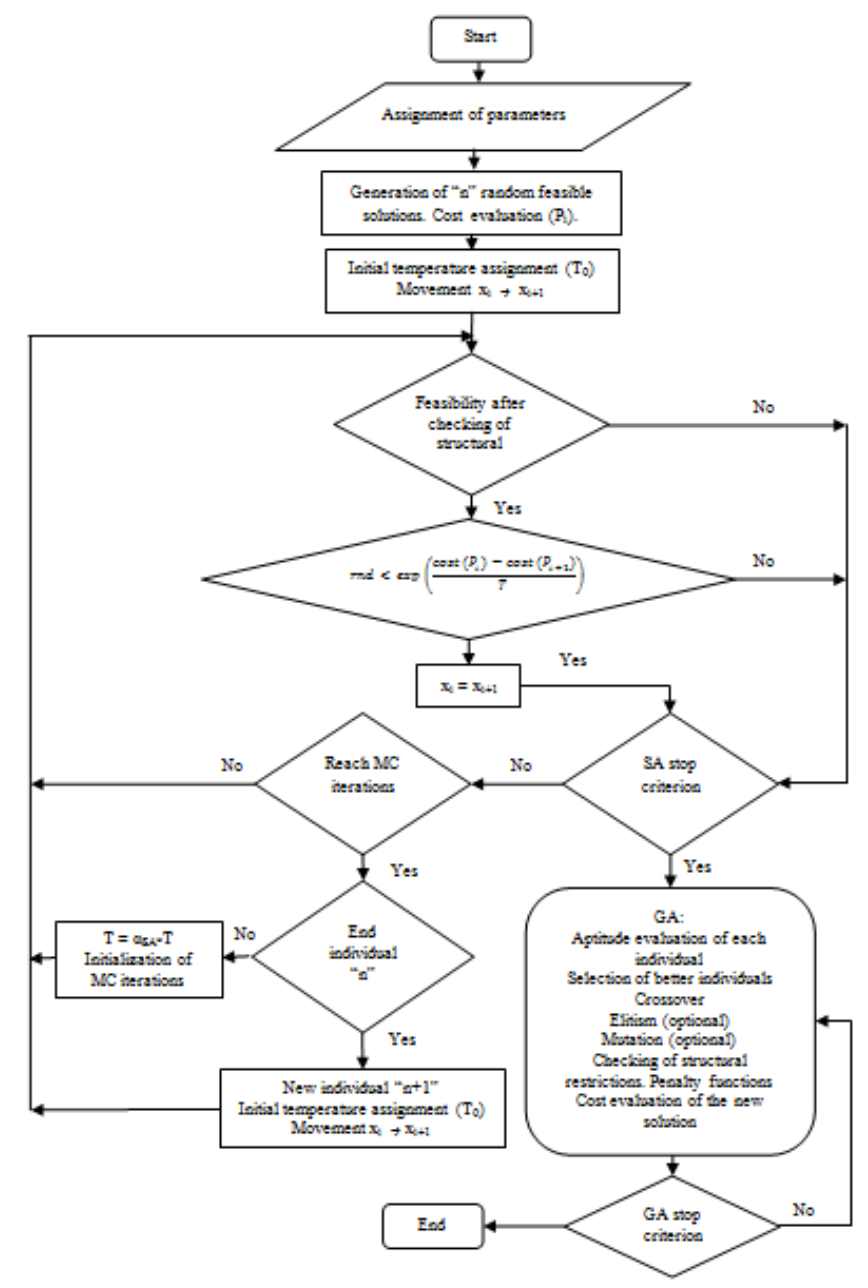

Figure 13: Flowchart of the MA process

The following parameters are considered for the local search: MC equal to 50, initial temperature ( $\left.T_{0}\right)$ equal to $5 \%$ of the cost, and stop criteria of 10,25 , and 50 chains. Likewise, the best heuristic obtained by the GA is chosen. The parameters are 500 individuals, 200 generations, elitism, a crossover value of 0.5 , and mutation $=4$. Nine executions are run for each of the three stop criteria. The results are shown in Table 6, where the average cost refers to the average of the values of the nine executions. It is worth noting that the computing time increases by 194 to $575 \%$, compared to GA. However, improvements of 2.2, 6.1, and $9.8 \%$ are observed for 10, 25, and 50 chains, respectively.

Figure 14 shows the evolution of average and minimum costs as the number of generations increases. A behavior similar to that of other metaheuristics can be observed, where the average values decrease rapidly in the beginning. Then, the cost results decrease much more slowly until they become practically constant. Comparing the results of MA with those of TAMO, the average cost (119703 $€)$ and the minimum cost 
(116933€) were 9.7 and $10.1 \%$ higher than those achieved with TAMO, respectively. Regarding the computing time, the MA heuristic needed more than seven times the processing time of TAMO.

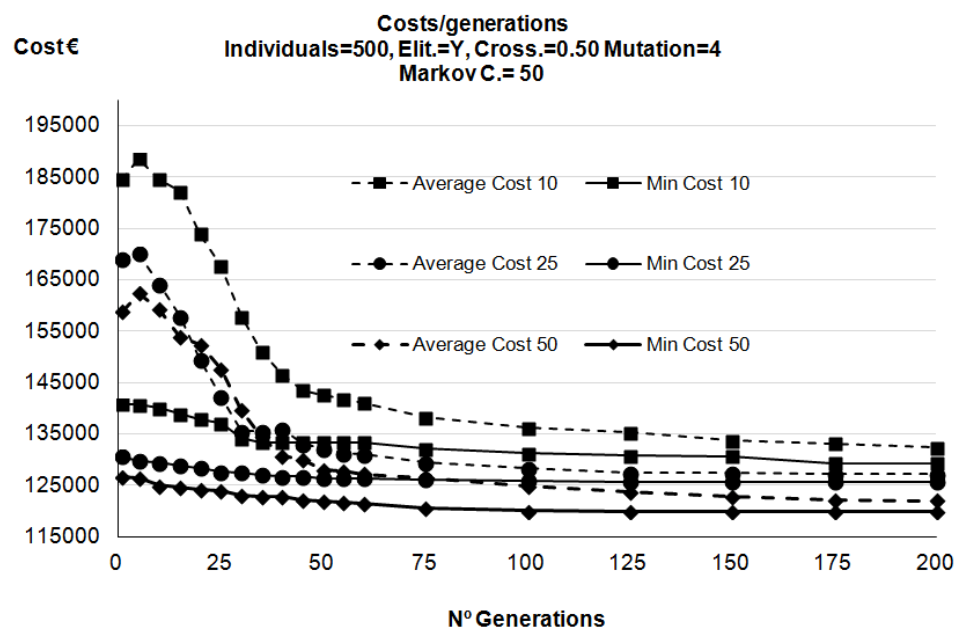

Figure 14: The evolution of average and minimum costs of MA

\section{Comparison of the results}

Table 7 summarizes the values of the best parameters obtained from the applied heuristics: DLS, TAMO, $\mathrm{GA}_{1}$ (without elitism), $\mathrm{GA}_{2}$ (with elitism), $\mathrm{GA}_{3}$ (with elitism and mutation =4), and MA. Additionally, the values obtained with SAMO [30] are incorporated in the tables. The average costs, minimum cost, average time, and increment of the average costs with respect to TAMO are included. The heuristic that achieves the best results is TAMO. However, SAMO only increases the cost by $2.4 \%$ (S3) and $3.8 \%$ (S12). MA, DLS, GA3, GA2, and GA1 follow with cost increments of 11.0, 19.0, 23.0, 28.7, and 33.0\%, respectively.

Table 8 summarizes the geometry, concrete, and reinforcement for the best solutions obtained by each heuristic. The beam depth varies between 1.69 and $1.94 \mathrm{~m}$. The three local search heuristics (DLS, TAMO, and SAMO) search for big beam depths with reduced thickness. The lower depth values coincide with the worst solutions. The best solution has a beam depth of $1.93 \mathrm{~m}$, which is equivalent to a ratio of depth to span length of 1/18.1. This value is close to the limit imposed (1/18).

There is a trend towards economization of the concrete volume, providing the best inertia while at the same time being as light as possible. This is reflected by high beams and small thicknesses, leading to less need for prestressing. The best results are achieved with minimal prestressing steel in the top flanges, but enough to prevent cracking during the tensioning phase. In addition, no strands are needed in the third layer. In an attempt to lighten the structure, higher-strength concrete, with values between 40 and $50 \mathrm{MPa}$, is used in the beams. 
The beam depth $h_{l}$, bottom flange width $b_{l}$, and number of strands of the TAMO solution are similar to those of the SAMO solution, but the minor thickness of the bottom flanges $b_{l}$ is compensated by concrete of greater grade (HP-45). Regarding the slab, the thickness $e_{4}$ acquires values between 0.19 and $0.27 \mathrm{~m}$. TAMO gives a thickness $(0.26 \mathrm{~m})$ that is almost the highest one and the highest concrete grade (HA-40). The width of the flanges $\left(b_{3}\right)$ should be short since it does not improve the flexure capacity.

It is worth noting that the use of elitism or non-elitism in the GA does not affect the geometry of the best solutions, as the values of the variables are the same. However, Table 9 shows the cost differences in the passive reinforcement. The lowest total steel quantities correspond to TAMO, followed by DLS and SAMO. Table 10 shows the concrete volume in the beams and slab. The larger thicknesses of the slabs obtained from TAMO lead to a greater concrete volume compared with SAMO (20.1\%). This allows the amount of reinforcement to be reduced compared to SAMO (42.2\%) and DLS (34.0\%). In the beam, the volume of concrete given by TAMO is the smallest. The amounts of reinforcing steel given by TAMO, DLS, and MA are similar and are smaller than the amount given by SAMO.

\section{Conclusions}

Four algorithms are compared for the efficient design of precast-prestressed U-beam road bridges. DLS, TAMO, GA, and MA are used to find cost-optimized solutions automatically. The results achieved by SAMO [30] for the same problem are incorporated. The conclusions are as follows:

- The most efficient move obtained in DLS, namely V9 (random variation of nine variables), was used for the other local search heuristic.

- TAMO was shown to be the most efficient procedure, closely followed by SAMO. In addition, the processing times for these two are acceptable for utilization in real cases. The best results for TAMO were achieved with a chain length of 5000 iterations and a reduction coefficient of 0.95 .

- Regarding GA, elitism improves the cost results. Compared to non-elitism, the solutions are $3.1 \%$ cheaper. The calibration recommends a population size of 500 individuals and a crossover value of 0.5 .

- Comparing MA with GA, the first raises the computing time by 194 to $575 \%$ but improves the cost result by $9.8 \%$. 
- $\mathrm{SAMO}_{\mathrm{S} 3}, \mathrm{SAMO}_{\mathrm{S1} 2}, \mathrm{MA}$, DLS, $\mathrm{GA}_{3}, \mathrm{GA}_{2}$, and $\mathrm{GA}_{1}$ increase the cost results by 2.4, 3.8, 11.0, 19.0, 23.0, 28.7, and 33.0\%, respectively, with respect to the average achieved by TAMO.

- The structural results of the three local search heuristics (DLS, TAMO, and SAMO) show a trend towards the maximum beam depth with minimum thicknesses.

- The greater slab thicknesses obtained by TAMO, with respect to SAMO, are compensated with less passive reinforcement. However, TAMO gives smaller beams and a larger amount of reinforcement.

- In the attempt to lighten the structure, it is advisable to use higher-strength concretes of between 40 to $50 \mathrm{MPa}$ for the beams. Regarding the slab, the greater the depth, the lower the concrete strength. The best values range between 35 and $40 \mathrm{MPa}$. The optimization tends towards short dimensions for the top flanges of the beam and minimal prestressing steel in the top flanges, but enough to prevent cracking.

\section{Acknowledgments}

The Spanish Ministry of Economy and Competitiveness along with FEDER funding (research project BIA2014-56574-R) financially supported this research. The authors are grateful for the thorough revision of the manuscript by Phillip Zastrow and Francisca Molina-Moreno.

\section{References}

[1] A. Yee, Social and environmental benefits of precast concrete technology, PCI Journal 46 (3) (2001) $14-19$.

[2] V.K. Koumousis, S.J. Arsenis, Genetic algorithms in optimal detailed design of reinforced concrete members, Computer-Aided Civil and Infrastructure Engineering 13 (1) (1998) 43-52.

[3] E.K. Zavadskas, T. Vilutiene, Z. Turskis, J. Saparauskas, Multi-criteria analysis of projects' performance in construction, Archives of Civil and Mechanical Engineering 14 (1) (2014) 114-121.

[4] M. Medineckiene, E.K. Zavadskas, F. Bjork, Z. Turskis, Multi-criteria decision-making system for sustainable building assessment/certification, Archives of Civil and Mechanical Engineering 15 (1) (2015) $11-18$.

[5] C. Blum, A. Roli, Metaheuristics in combinatorial optimization: overview and conceptual comparison, ACM Computing Surveys 35 (3) (2003) 268-308.

[6] R.J. Balling, X. Yao, Optimization of reinforced concrete frames, Journal of Structural Engineering 123 (2) (1997) 193-202. 
[7] C.A. Coello, A.D. Christiansen, F. Santos, A simple genetic algorithm for the design of reinforced concrete beams, Engineering with Computers 13 (4) (1997) 185-196.

[8] M.Z. Cohn, A.S. Dinovitzer, Application of structural optimization, Journal of Structural Engineering 120 (2) (1994) 617-649.

[9] W. Hare, J. Nutini, S. Tesfamariam, A survey of non-gradient optimization methods in structural engineering, Advances in Engineering Software 59 (2013) 19-28.

[10] A. Carbonell, F. González-Vidosa, V. Yepes, Design of reinforced concrete road vaults by heuristic optimization, Advances in Engineering Software 42 (4) (2011) 151-159.

[11] A. Kesy, A. Kadziela, Construction optimization of hydrodynamic torque converter with application of genetic algorithm, Archives of Civil and Mechanical Engineering 11 (4) (2011) 905-920.

[12] H. Cai, A.J. Aref, A genetic algorithm-based multi-objective optimization for hybrid fiber reinforced polymeric deck and cable system of cable-stayed bridges, Structural and Multidisciplinary Optimization 52 (3) (2015) 583-594.

[13] W. Beluch, T. Burczyński, Two-scale identification of composites' material constants by means of computational intelligence methods, Archives of Civil and Mechanical Engineering 14 (4) (2014) 636-646.

[14] P. Fedeliński, R. Górski, Optimal arrangement of reinforcement in composites, Archives of Civil and Mechanical Engineering 15 (2) (2015) 525-531.

[15] V. Yepes, T. García-Segura, J.M. Moreno-Jiménez, A cognitive approach for the multi-objective optimization of RC structural problems, Archives of Civil and Mechanical Engineering 15 (4) (2015) 10241036.

[16] M. Kripka, G.F. Medeiros, A.C.C. Lemonge, Use of optimization for automatic grouping of beam cross-section dimensions in reinforced concrete building structures, Engineering Structures 99 (2015) 311318.

[17] C. Torres-Machí, V. Yepes, J. Alcalá, E. Pellicer, Optimization of high-performance concrete structures by variable neighborhood search, International Journal of Civil Engineering 11 (2) (2013) 9099.

[18] S.M. Nigdeli, G. Bekdas, S. Kim, Z.W. Geem, A novel harmony search based optimization of reinforced concrete biaxially loaded columns, Structural Engineering and Mechanics 54 (6) (2015) 10971109.

[19] T. García-Segura, V. Yepes, Multiobjective optimization of post-tensioned concrete box-girder road bridges considering cost, CO2 emissions, and safety, Engineering Structures 125 (2016) 325-336.

[20] F.J. Martínez-Martín, F. González-Vidosa, A. Hospitaler, V. Yepes, A parametric study of optimum tall piers for railway bridge viaducts, Structural Engineering and Mechanics 45 (6) (2013) 723-740.

[21] T. García-Segura, V. Yepes, J.V. Martí, J. Alcalá, Optimization of concrete I-beams using a new hybrid glowworm swarm algorithm, Latin American Journal of Solids and Structures 11 (7) (2014) 1190-1205.

[22] S. Talatahari, A.H. Gandomi, X.S. Yang, S. Deb, Optimum design of frame structures using the Eagle Strategy with Differential Evolution, Engineering Structures 91 (2013) 16-25.

[23] C.V. Camp, A. Akin, Design of retaining walls using big bang-big crunch optimization, Journal of Structural Engineering 138 (3) (2012) 438-448. 
[24] M. A. Hassanain, R.E. Loov, Cost optimization of concrete bridge infrastructure, Canadian Journal of Civil Engineering 30 (5) (2003) 841-849.

[25] S. Hernández, A.N. Fontan, J. Díaz, D. Marcos, VTOP. An improved software for design optimization of prestressed concrete beams, Advances in Engineering Software 41 (3), (2010) 415-421.

[26] S. Ohkubo, P.B.R. Dissanayake, K. Taniwaki, An approach to multicriteria fuzzy optimization of a prestressed concrete bridge system considering cost and aesthetic feeling, Structural Optimization 15 (2) (1998) 132-140.

[27] G.F. Sirca, H. Adeli, Cost optimization of prestressed concrete bridges, Journal of Structural Engineering 131 (3) (2005) 380-388.

[28] R. Ahsan, S. Rana, S. Nurul Ghani, Cost optimum design of posttensioned I-girder bridge using global optimization algorithm, Journal of Structural Engineering 138 (2) (2012) 273-284.

[29] T. García-Segura, V. Yepes, J. Alcalá, E. Pérez-López, Hybrid harmony search for sustainable design of post-tensioned concrete box-girder pedestrian bridges, Engineering Structures 92 (2015) 112-122.

[30] J.V. Martí, F. Gonzalez-Vidosa, V. Yepes, J. Alcalá, Design of prestressed concrete precast road bridges with hybrid simulated annealing, Engineering Structures 48 (2013) 342-352.

[31] M. Fomento, Code on Structural Concrete EHE-08, Ministerio de Fomento, Madrid, Spain, 2008 (in Spanish).

[32] M. Fomento, IAP-98: Code on the actions for the design of road bridges, Madrid, Spain, 1998.

[33] I. Payá-Zaforteza, V. Yepes, F. González-Vidosa, A. Hospitaler, On the Weibull cost estimation of building frames designed by simulated annealing, Meccanica 45 (5) (2010) 693-704.

[34] G. Dueck, T. Scheuer, Threshold accepting: A general purpose optimization algorithm appearing superior to simulated annealing, Journal of Computational Physics 90 (1990) 161-175.

[35] J. Medina, Estimation of incident and reflected waves using simulated annealing, Journal of Waterway, Port, Coastal, and Ocean Engineering 127 (4) (2001) 213-221.

[36] A. Luz, V. Yepes, F. González-Vidosa, J.V. Martí. Design of open reinforced concrete abutments road bridges with hybrid stochastic hill climbing algorithms, Informes de la Construcción 67 (540) (2015) e114.

[37] J.H. Holland, Adaptation in Natural and Artificial Systems, 1975. https://mitpress.mit.edu/books/adaptation-natural-and-artificial-systems (accessed November 10, 2016).

[38] P. Moscato, On Evolution, Search, Optimization, Genetic Algorithms and Martial Arts - Towards Memetic Algorithms, Caltech Concurrent Computation Program. (report 826) (1989). http://citeseerx.ist.psu.edu/viewdoc/summary?doi=10.1.1.27.9474 (accessed November 9, 2016). 


\section{Tables and Figures}

Table 1. Unit prices of the materials in euros

\begin{tabular}{lcc}
\multicolumn{1}{c}{ Description } & Price of beam $(€)$ & Price of slab $(€)$ \\
\hline kg reinforcing steel (B-500-S) & 2.63 & 1.40 \\
$\mathrm{~kg}$ prestressing steel (Y-1860-S7) & 3.38 & - \\
$\mathrm{m}$ of beam mould & 75.11 & - \\
$\mathrm{m}^{2}$ of slab formwork & - & 30.00 \\
$\mathrm{~m}^{3}$ of concrete HA-25 & - & 64.99 \\
$\mathrm{~m}^{3}$ of concrete HA-30 & - & 69.95 \\
$\mathrm{~m}^{3}$ of concrete HA-35 & - & 74.03 \\
$\mathrm{~m}^{3}$ of concrete HA-40 & - & 79.12 \\
$\mathrm{~m}^{3}$ of concrete HP-35 & 122.25 & - \\
$\mathrm{m}^{3}$ of concrete HP-40 & 133.40 & - \\
$\mathrm{m}^{3}$ of concrete HP-45 & 142.15 & - \\
$\mathrm{m}^{3}$ of concrete HP-50 & 152.89 & - \\
\hline
\end{tabular}


Table 2. Input parameters for the analysis

\begin{tabular}{ll}
\hline Loading parameters & \\
\hline Concrete bridge barrier width & $2 \times 0.50 \mathrm{~m}$ \\
Thickness of the wearing surface & $t_{w s}=0.09 \mathrm{~m}$ \\
Concrete bridge barrier loads & $2 \times 5.0 \mathrm{kN} / \mathrm{m}$ \\
\hline Geometric parameters & \\
\hline PC precast bridge width & $W=12.00 \mathrm{~m}$ \\
Spacing between beams & $S_{v}=6.00 \mathrm{~m}$ \\
Inclination, top flange tablet & $n_{s 3}=3$ \\
Top flange division & $S_{3}=3$ \\
Inclination, bottom flange tablet & $n_{i 3}=3$ \\
Bottom flange division & $i_{4}=4$ \\
Web inclination & $80^{\circ}$ \\
Minimum beam slenderness & $L / 18$ \\
Bearing center to beam face distance & $0.47 \mathrm{~m}$ \\
\hline
\end{tabular}

\begin{tabular}{ll}
\hline Reinforcement parameters & \\
\hline Passive reinforcing steel (B-500-S) & $f_{y k}=500 \mathrm{~N} / \mathrm{mm}^{2}$ \\
Active prestressing steel (Y1860-S7) & $f_{p k}=1700 \mathrm{~N} / \mathrm{mm}^{2}$ \\
Strand diameter & $\Phi_{s}=0.6 "$ \\
Beam surface reinforcement & $\Phi_{r}=8 \mathrm{~mm}$ \\
Strand sheaths & Levels 2 and 3 \\
Vertical slenderness of stirrups & 200 (length/diameter) \\
\hline Cost parameters & \\
\hline Transport distance (one way) & $T_{d}=50 \mathrm{~km}$ \\
Active prestressing steel crops & $25 \%$ \\
\hline Legislative and exposure parameters & \\
\hline Code regulation & EHE/IAP-98 \\
External ambient conditions & IIb (EHE) \\
\hline
\end{tabular}


Table 3. Results of the TAMO algorithm for 16 parameter combinations

\begin{tabular}{lrrrrrr}
\hline $\begin{array}{l}\text { Heuristic } \\
\text { number }\end{array}$ & $\alpha_{\mathrm{TA}}$ & $\mathrm{L}_{\mathrm{I}}$ & $\begin{array}{l}\text { Average } \\
\text { cost }(€)\end{array}$ & $\begin{array}{l}\text { Average } \\
\text { time }(\mathrm{s})\end{array}$ & $\begin{array}{l}\text { Minimum } \\
\text { cost }(€)\end{array}$ & $\begin{array}{l}\text { Deviation } \\
(\%)\end{array}$ \\
\hline $\mathrm{T} 1$ & 0.95 & 500 & 111073 & 3667 & 107919 & 2.92 \\
$\mathrm{~T} 2$ & 0.95 & 1000 & 111200 & 7463 & 107910 & 3.05 \\
$\mathrm{~T} 3$ & 0.95 & 2500 & 109312 & 18458 & 107970 & 1.24 \\
$\mathrm{~T} 4$ & 0.95 & 5000 & 107856 & 36958 & 106042 & 1.71 \\
$\mathrm{~T} 5$ & 0.90 & 500 & 114587 & 1931 & 108279 & 5.83 \\
$\mathrm{~T} 6$ & 0.90 & 1000 & 110305 & 3711 & 107825 & 5.99 \\
$\mathrm{~T} 7$ & 0.90 & 2500 & 109897 & 9318 & 106569 & 3.17 \\
$\mathrm{~T} 8$ & 0.90 & 5000 & 110452 & 19635 & 108363 & 2.08 \\
$\mathrm{~T} 9$ & 0.85 & 500 & 117418 & 1314 & 109169 & 7.56 \\
$\mathrm{~T} 10$ & 0.85 & 1000 & 114370 & 2661 & 107908 & 5.99 \\
$\mathrm{~T} 11$ & 0.85 & 2500 & 109552 & 6413 & 106191 & 3.17 \\
$\mathrm{~T} 12$ & 0.85 & 5000 & 110139 & 12977 & 107894 & 2.08 \\
$\mathrm{~T} 13$ & 0.80 & 500 & 118589 & 1074 & 110728 & 7.10 \\
$\mathrm{~T} 14$ & 0.80 & 1000 & 114232 & 2091 & 109139 & 4.67 \\
$\mathrm{~T} 15$ & 0.80 & 2500 & 112214 & 5074 & 108015 & 3.89 \\
$\mathrm{~T} 16$ & 0.80 & 5000 & 111134 & 9747 & 107874 & 3.02 \\
\hline
\end{tabular}


Table 4. GA results for a population size of 500 individuals

\begin{tabular}{|c|c|c|c|c|c|c|c|c|c|}
\hline \multirow[b]{2}{*}{ Crossover } & \multirow[b]{2}{*}{ Generations } & \multicolumn{4}{|c|}{ Without elitism } & \multicolumn{4}{|c|}{ With elitism } \\
\hline & & $\begin{array}{l}\text { Average } \\
\text { Cost }(€)\end{array}$ & $\begin{array}{l}\text { Time } \\
\text { (s) }\end{array}$ & $\begin{array}{c}\text { Best } \\
\text { Cost€) }\end{array}$ & $\begin{array}{c}\% \\
\text { Desv. }\end{array}$ & $\begin{array}{l}\text { Average } \\
\text { Cost }(€)\end{array}$ & $\begin{array}{c}\text { Time } \\
\text { (s) }\end{array}$ & $\begin{array}{c}\text { Best } \\
\text { Cost }(€)\end{array}$ & $\begin{array}{c}\% \\
\text { Desv. }\end{array}$ \\
\hline \multirow{9}{*}{0.25} & 10 & 157175 & 13948 & 147762 & $6.40 \%$ & 153560 & 13758 & 148212 & $3.60 \%$ \\
\hline & 25 & 154493 & 14607 & 144327 & $7.00 \%$ & 151048 & 14412 & 147340 & $2.50 \%$ \\
\hline & 50 & 150758 & 15705 & 144327 & $4.50 \%$ & 148592 & 15519 & 145186 & $2.40 \%$ \\
\hline & 75 & 149304 & 16804 & 144327 & $3.40 \%$ & 147512 & 16627 & 141425 & $4.30 \%$ \\
\hline & 100 & 147537 & 17902 & 141039 & $4.60 \%$ & 146825 & 17734 & 140179 & $4.70 \%$ \\
\hline & 125 & 146889 & 19001 & 136076 & $7.90 \%$ & 146567 & 18842 & 139137 & $5.30 \%$ \\
\hline & 150 & 146516 & 20099 & 136076 & $7.70 \%$ & 146433 & 19949 & 138290 & $5.90 \%$ \\
\hline & 175 & 146408 & 21197 & 136076 & $7.60 \%$ & 146337 & 21056 & 138290 & $5.80 \%$ \\
\hline & 200 & 146285 & 22296 & 135709 & $7.80 \%$ & 146160 & 22164 & 137442 & $6.30 \%$ \\
\hline \multirow{9}{*}{0.5} & 10 & 156951 & 13928 & 149382 & $5.10 \%$ & 155907 & 13745 & 149470 & $4.30 \%$ \\
\hline & 25 & 151264 & 14590 & 145577 & $3.90 \%$ & 148711 & 14397 & 143798 & $3.40 \%$ \\
\hline & 50 & 148806 & 15696 & 139770 & $6.50 \%$ & 142763 & 15477 & 137458 & $3.90 \%$ \\
\hline & 75 & 147387 & 16803 & 139702 & $5.50 \%$ & 140890 & 16558 & 134412 & $4.80 \%$ \\
\hline & 100 & 146284 & 17909 & 139702 & $4.70 \%$ & 140117 & 17638 & 133377 & $5.10 \%$ \\
\hline & 125 & 145771 & 19016 & 138275 & $5.40 \%$ & 139830 & 18719 & 133332 & $4.90 \%$ \\
\hline & 150 & 145492 & 20122 & 138275 & $5.20 \%$ & 139285 & 19799 & 132618 & $5.00 \%$ \\
\hline & 175 & 145266 & 21228 & 138275 & $5.10 \%$ & 138885 & 20879 & 132618 & $4.70 \%$ \\
\hline & 200 & 145105 & 22335 & 137207 & $7.80 \%$ & 138743 & 21960 & 132618 & $4.60 \%$ \\
\hline \multirow{9}{*}{0.75} & 10 & 156620 & 13952 & 149816 & $4.50 \%$ & 154134 & 13763 & 147789 & $4.30 \%$ \\
\hline & 25 & 151442 & 14618 & 133683 & $13.30 \%$ & 146274 & 14414 & 136229 & $7.40 \%$ \\
\hline & 50 & 147701 & 15491 & 127325 & $16.00 \%$ & 142436 & 15498 & 130041 & $9.50 \%$ \\
\hline & 75 & 145189 & 16365 & 127325 & $14.00 \%$ & 141470 & 16583 & 128945 & $9.70 \%$ \\
\hline & 100 & 144271 & 17238 & 126613 & $14.00 \%$ & 140903 & 17667 & 128618 & $9.60 \%$ \\
\hline & 125 & 144061 & 18112 & 126613 & $13.80 \%$ & 140574 & 18752 & 128293 & $9.60 \%$ \\
\hline & 150 & 143741 & 18985 & 126450 & $13.70 \%$ & 140354 & 19836 & 128261 & $9.40 \%$ \\
\hline & 175 & 143551 & 19858 & 126450 & $13.50 \%$ & 140217 & 20920 & 128261 & $9.30 \%$ \\
\hline & 200 & 143314 & 20732 & 126418 & $13.40 \%$ & 140084 & 22005 & 128261 & $9.20 \%$ \\
\hline
\end{tabular}

Table 5. Application of mutation in GA for 500 individuals, 0.5 crossover, and 200 generations

\begin{tabular}{ccrccc}
\hline Mutation & Average Cost $(€)$ & Time $(\mathrm{s})$ & Best Cost $(€)$ & $\%$ MD & $\%$ Improvement \\
\hline 0 & 138,743 & 21,964 & 132,618 & $4.6 \%$ & - \\
1 & 134,846 & 22,469 & 130,424 & $3.4 \%$ & $2.8 \%$ \\
2 & 133,992 & 22,479 & 126,366 & $6.0 \%$ & $3.4 \%$ \\
3 & 133,091 & 22,487 & 125,187 & $6.3 \%$ & $4.1 \%$ \\
4 & 132,678 & 22,499 & 123,078 & $7.8 \%$ & $4.4 \%$ \\
5 & 132,707 & 22,131 & 125,345 & $5.9 \%$ & $4.4 \%$ \\
\hline
\end{tabular}


Table 6. Results of MA

\begin{tabular}{|c|c|c|c|c|c|c|}
\hline Markov C. & $\begin{array}{l}\text { Chain } \\
\text { Number }\end{array}$ & $\begin{array}{l}\text { Average } \\
\operatorname{Cost}(€)\end{array}$ & Seconds & $\begin{array}{c}\text { Best } \\
\text { Cost }(€)\end{array}$ & $\% \mathrm{MD}$ & $\begin{array}{c}\% \\
\text { Improv./GA }\end{array}$ \\
\hline \multirow[t]{3}{*}{50} & 10 & 129,718 & 43,639 & 124,446 & $4.2 \%$ & $2.2 \%$ \\
\hline & 25 & 124,564 & 76,934 & 119,332 & $4.4 \%$ & $6.1 \%$ \\
\hline & 50 & 119,703 & 129,441 & 116,933 & $2.4 \%$ & $9.8 \%$ \\
\hline
\end{tabular}

Table 7. Summary of the heuristics

\begin{tabular}{lrrrrrrrr}
\hline & DLS & $\mathrm{SAMO}_{\mathrm{S} 3}$ & $\mathrm{SAMO}_{\mathrm{S} 12}$ & $\mathrm{TAMO}$ & $\mathrm{GA}_{1} *$ & $\mathrm{GA}_{2} *$ & $\mathrm{GA}_{3} *$ & $\mathrm{MA}$ \\
\hline Average cost $(€)$ & 128309 & 110477 & 111903 & 107856 & 143414 & 138863 & 132678 & 119703 \\
Best cost $(€)$ & 115459 & 109004 & 108008 & 106042 & 126418 & 127969 & 123078 & 116933 \\
$\begin{array}{l}\text { Average time (s.) } \\
\begin{array}{l}\text { \% Average cost/TAMO } \\
\text { cost }\end{array}\end{array}$ & 8122 & 18322 & 12986 & 36233 & 20732 & 21960 & 22499 & 129441 \\
\hline
\end{tabular}

$* \mathrm{GA}_{1}$ without elitism. $\mathrm{GA}_{2}$ with elitism. $\mathrm{GA}_{3}$ with elitism and mutation $=4$

Table 8. Best results: geometry, concrete and active reinforcement

\begin{tabular}{ccccccccccccccc}
\hline & Cost $(€)$ & $\begin{array}{r}h_{1} \\
(\mathrm{~m})\end{array}$ & $\begin{array}{r}e_{4} \\
(\mathrm{~m})\end{array}$ & $\begin{array}{r}b_{1} \\
(\mathrm{~m})\end{array}$ & $\begin{array}{r}b_{3} \\
(\mathrm{~m})\end{array}$ & $\begin{array}{r}e_{1} \\
(\mathrm{~m})\end{array}$ & $\begin{array}{r}e_{2} \\
(\mathrm{~m})\end{array}$ & $\begin{array}{r}e_{3} \\
(\mathrm{~m})\end{array}$ & $\begin{array}{r}f_{c, \text { beam }} \\
(\mathrm{MPa})\end{array}$ & $\begin{array}{r}f_{c, \text { slab }} \\
(\mathrm{MPa})\end{array}$ & $\begin{array}{r}p_{1} \\
(\mathrm{n})\end{array}$ & $\begin{array}{r}p_{2} \\
(\mathrm{n})\end{array}$ & $\begin{array}{r}p_{3} \\
(\mathrm{n})\end{array}$ & $\begin{array}{r}p_{4} \\
(\mathrm{n})\end{array}$ \\
\hline DLS $^{115459}$ & 1.93 & 0.27 & 1.90 & 0.38 & 0.25 & 0.10 & 0.31 & 45 & 40 & 35 & 26 & 0 & 2 \\
SAMO $_{12}$ & 108008 & 1.94 & 0.19 & 1.99 & 0.29 & 0.18 & 0.10 & 0.23 & 40 & 40 & 36 & 20 & 0 & 2 \\
$\mathrm{TAMO}_{1} *$ & 104184 & 1.93 & 0.26 & 2.00 & 0.33 & 0.15 & 0.10 & 0.28 & 45 & 40 & 37 & 20 & 0 & 2 \\
$\mathrm{GA}_{2} *$ & 126418 & 1.78 & 0.24 & 1.92 & 0.33 & 0.17 & 0.16 & 0.20 & 45 & 30 & 35 & 29 & 0 & 6 \\
$\mathrm{GA}_{3} *$ & 127969 & 1.78 & 0.24 & 1.92 & 0.33 & 0.17 & 0.16 & 0.20 & 45 & 30 & 35 & 29 & 0 & 6 \\
$\mathrm{MA}^{*}$ & 123078 & 1.69 & 0.22 & 1.98 & 0.41 & 0.23 & 0.14 & 0.32 & 40 & 35 & 36 & 34 & 0 & 6 \\
\hline
\end{tabular}

$* \mathrm{GA}_{1}$ without elitism. $\mathrm{GA}_{2}$ with elitism. $\mathrm{GA}_{3}$ with elitism and mutation=4

Table 9. Best results: passive reinforcement

\begin{tabular}{lrrrrrrr}
\hline Steel & DLS & SAMO $_{\text {S12 }}$ & TAMO & GA $_{1}^{*}$ & $\mathrm{GA}_{2} *$ & $\mathrm{GA}_{3} *$ & \multicolumn{1}{c}{ MA } \\
\hline In beams (kg) & 6325 & 5562 & 6803 & 8554 & 8496 & 7167 & 6359 \\
In slab (kg) & 17341 & 19561 & 10860 & 22105 & 22181 & 20015 & 19419 \\
Total (kg) & 23666 & 25123 & 17664 & 30659 & 30677 & 27182 & 25778 \\
\% Steel/record & $34.0 \%$ & $42.2 \%$ & $0.0 \%$ & $73.6 \%$ & $73.7 \%$ & $53.9 \%$ & $45.9 \%$ \\
\hline
\end{tabular}

$* \mathrm{GA}_{1}$ without elitism. $\mathrm{GA}_{2}$ with elitism. $\mathrm{GA}_{3}$ with elitism and mutation=4

Table 10. Best results: concrete in beams and slab

\begin{tabular}{|c|c|c|c|c|c|c|c|}
\hline Concrete & DLS & SAMO $_{\text {S12 }}$ & TAMO & $\mathrm{GA}_{1} *$ & $\mathrm{GA}_{2} *$ & $\mathrm{GA}_{3} *$ & MA \\
\hline In beams $\left(\mathrm{m}^{3}\right)$ & 74.575 & 61.206 & 59.753 & 67.906 & 67.906 & 78.263 & 66.378 \\
\hline In slab $\left(\mathrm{m}^{3}\right)$ & 116.446 & 81.943 & 112.133 & 103.507 & 103.507 & 94.882 & 99.194 \\
\hline Total $\left(\mathrm{m}^{3}\right)$ & 191.021 & 143.149 & 171.886 & 171.413 & 171.413 & 173.145 & 165.572 \\
\hline$\%$ Concrete/record & $33.4 \%$ & $0.0 \%$ & $20.1 \%$ & $19.7 \%$ & $19.7 \%$ & $20.9 \%$ & $15.7 \%$ \\
\hline
\end{tabular}


